\title{
EXPLORANDO UM CONTO DE FICÇÃO CIENTÍFICA: GUIA PEDAGÓGICO PARA CONSTRUIR PONTES ENTRE LITERATURA, CIÊNCIAS HUMANAS E QUÍMICA EM SALA
}

DE AULA

\author{
Pablo Wolf Oliveira \\ Nadja Paraense dos Santos
}

\section{Introdução}

A construção do produto educacional foi fruto do desenvolvimento da dissertação de Mestrado de Oliveira (2019). O presente capítulo tem como objetivo mostrar a sugestão de um Caderno Pedagógico desenvolvido como proposta para aproximar conhecimentos e reflexões sobre conceitos de Química, História e Sociedade ao ensino através de um conto de ficção científica, além da avaliação de professores ao conhecer este caderno e as atividades nele sugeridas.

Química também é cultura e este fato precisa ser mostrado na escola. Usa-se o termo cultura aqui no sentido de entendermos que a construção do conhecimento das ciências naturais não é uma mera observação, descri- 
ção e explicação dos fenômenos da natureza. Pimentel (2010) reconhece que existem estreitas relações entre natureza e sociedade na ciência, pois quando surge uma nova ideia científica ou fato científico é importante entender o contexto social e político desse surgimento, as ideias filosóficas vigentes, a história, as ideias e as motivações dos pesquisadores e instituições envolvidos. $\mathrm{O}$ autor aponta que existe artificialidade e humanidade no conhecimento da natureza e afirma que "todo feito científico, toda teoria ou toda prática relacionada com o conhecimento da natureza é um feito profundamente cultural, assim como também é um feito social" (PIMENTEL,2010, p.418).

Gurgel e Watanabe (2017) também defendem o ensino das ciências como cultura e partindo dessa ideia fazem um trabalho envolvendo narrativas no ensino de Física para levarem os alunos a reconhecerem-nas como parte de sua cultura. Os autores expõem que há uma carência de entendimento do conhecimento científico enquanto cultura, sendo a última mais associada a manifestações artísticas, sendo necessário "pensar a própria ciência como uma forma de cultura, manifestação de um grupo social e parte da cultura de uma sociedade" (Idem, p.25).

Neste trabalho escolheu-se como referencial para a construção da ideia de se trabalhar o conhecimento científico como manifestação cultural o pensamento do 
físico e escritor inglês Charles Percy Snow (1905-1980). A expressão duas culturas foi usada por Charles Snow para sua palestra na University of Cambridge, publicada no mesmo ano de 1959, cuja tradução brasileira data de 1995. O livro "As duas culturas e uma segunda leitura" consta de duas partes. A primeira parte, "A palestra rede, 1959", consiste na palestra dada. A segunda parte, "As duas culturas: uma segunda leitura" (1963) consiste nas respostas dadas por Snow às críticas referentes à palestra. Antes de discutir a problematização trazida por Charles Percy Snow, é importante procurar entender o significado da palavra cultura, já que é um termo de muitas acepções.

Oliveira e Alves (2015) analisam o conceito de cultura na perspectiva de alguns autores e evidenciam algumas concepções que melhor permitem entender o referido conceito, como por exemplo:

a) Para Michel de Certeau (1925-1986), uma sociedade é caracterizada como diferente da outra por comportamentos, instituições, ideologias e mitos que são referências para determinada sociedade e assim constituem a sua cultura (OLIVEIRA e ALVES,2015, p.16).

b) Para Terry Eagleton (1943-atual), a cultura permite diferenciar uma sociedade de outra e está relacionada àquilo que dá significado à vida de uma pessoa, como por exemplo, afeto, relacionamento, memória, comunidade, prazer intelectual e emocional (IDEM, p.16). 
A partir desses conceitos podemos perceber que dois agrupamentos humanos organizados podem ter poucas características em comum, tornando as diferenças bastante visíveis. Mesmo considerando as diferenças dentro de um mesmo agrupamento, as características em comum formam uma determinada cultura.

O físico e escritor inglês Charles Percy Snow (1905-1980) propõe a aproximação entre "Duas Culturas", percebendo a existência de dois grupos com características distintas que precisam dialogar pelo bem da construção do conhecimento e da sociedade.

Snow referiu-se a duas culturas pensando em dois grupos de intelectuais na Inglaterra do início do século XX que se apresentavam com pensamentos e interesses diferentes: os cientistas e os literatos.

As duas culturas polarizadas segundo este autor são a cultura tradicional e a cultura científica e defende que essa polarização é danosa por trazer perdas nos aspectos prático, intelectual e criativo.

Ele chama de cultura tradicional (baseado no contexto em que vivia) aquela que não é científica, afirmando que existe "um sabor não-científico em toda a cultura "tradicional" (...) a ponto de se tornar anticientífico" (SNOW, 1995, p.29) e remete a essa cultura quando fala de artistas de uma forma geral e em especial dos literatos. 
Entretanto, é possível deduzir que as ciências humanas, como a História, também entram na cultura tradicional no pensamento de Snow. Ao se referir ao fato de os profissionais científicos terem maiores chances e vantagens em relação à situação financeira, ele diz: "os jovens cientistas sabem que com qualquer diploma que seja conseguirão um emprego confortável, enquanto seus contemporâneos e congêneres em Inglês ou História terão sorte se ganharem 60 \% do que eles ganharem" (SNOW, 1995, p.29). A mesma situação é citada para os profissionais de Artes, que são incluídos na cultura tradicional. A referência à cultura científica é dada para físicos, biólogos, enfim, para quem trabalha com ciências exatas e da natureza, bem como para os profissionais que utilizam tecnologias associadas a esses conhecimentos, como os engenheiros.

Uma vez entendido o significado do termo $A s$ Duas Culturas, Snow propõe a superação do distanciamento e falta de diálogo aqui colocado através do que ele chama de Terceira Cultura.

Almeida Filho (2007) esclarece o significado da Terceira Cultura proposta por Snow, sendo aquela "formada por humanistas com um bom conhecimento de ciência e por cientistas com forte sensibilidade às artes e humanidades, e que poderiam fazer a ponte entre as duas culturas" (ALMEIDA FILHO, 2007, p.9). 
Snow esclarece que a Terceira Cultura deve "estar em boas relações com a cultura científica” (SNOW,1995, p.95), referindo-se com isso à importância de os humanistas terem conhecimentos das ciências exatas e naturais e de tecnologia. Sua ideia sobre Terceira Cultura pode ser sintetizada na seguinte fala:

No entanto, com sorte, podemos educar uma grande proporção de nossas melhores inteligências para que não desconheçam a experiência criativa, tanto na ciência quanto na arte, não ignorem as possibilidades da ciência aplicada, o sofrimento remediável dos seus contemporâneos e as responsabilidades que, uma vez estabelecidas, não podem mais ser negadas". (SNOW,1995, p.128)

Pode-se inferir que para este autor a Terceira Cultura se estabeleceria a partir de indivíduos que tenham conhecimentos científicos e artísticos, façam uso da razão e ao mesmo tempo da criatividade, utilizem esses conhecimentos para o bem comum e pensem nas responsabilidades inerentes ao uso dos conhecimentos. Percebo que a Terceira Cultura consiste no uso do conhecimento artístico, filosófico e científico de forma articulada para que as pessoas possam viver com conhecimento, sabedoria e qualidade de vida.

Na prática escolar a interdisciplinaridade é uma forma de aproximar "as duas culturas", ou seja, colocan- 
do o pensamento de Snow de uma forma atual e aplicada ao contexto escolar, falamos da aproximação entre diferentes áreas de conhecimento escolar, como Ciências da Natureza de Ciências Humanas e estas com o estudo de linguagens e de Filosofia, ou entre diferentes disciplinas escolares, como Química de História, por exemplo.

Oliveira e Santos (2017) esclarecem que não existe uma única concepção de interdisciplinaridade, mas percebe que todas elas caminham no sentido de superar a fragmentação do conhecimento. Podemos considerar que "existe uma posição consensual com relação ao sentido e à finalidade da interdisciplinaridade: ela busca responder à necessidade de superação da visão fragmentada nos processos de produção e socialização do conhecimento" (THIESEN,2008, p.545).

Para analisar uma prática de ensino e buscar os aspectos interdisciplinares, é preciso ter em mente qual a visão de interdisciplinaridade escolhida. Estou de acordo com a visão de Cordiolli (2002), que explica:

A interdisciplinaridade corresponde à produção ou processo de relações entre saberes, a partir de uma disciplina ou de um tema sem as limitações de domínios ou objetos impostos pela especialização das ciências. A característica básica de uma ação interdisciplinar é a de pesquisador, estudioso, professor ou aluno que, ao explorar um tema, recorre a conceitos e instrumentos de 
outras áreas do conhecimento ou disciplina. (CORDIOLLI, 2002, p.19)

Dessa forma, a ação interdisciplinar corresponde a uma busca pela ampliação do conhecimento sem que este esteja limitado a uma única disciplina ou área de conhecimento. Na prática escolar, uma forma de pensar a ocorrência da interdisciplinaridade é:

No espaço escolar e acadêmico, organizados em disciplinas, a prática interdisciplinar refere-se à ação que parte de uma disciplina, mas utiliza de conceitos ou instrumentos de outras para tratar das questões previstas em seus objetivos. O professor que atua numa perspectiva interdisciplinar é aquele que domina o conteúdo de sua área e recorre a outras disciplinas para explorar plenamente os temas de que está tratando. Numa proposta não-disciplinar, todo tema, mesmo estando ancorado em uma área do saber, requer práticas pedagógicas que tendem a ser interdisciplinares. (CORDIOLLI, 2002, p.19 e 20)

Conforme explica Haas (2011) ao estudar o pensamento de Ivani Fazenda sobre interdisciplinaridade e atitude pedagógica, "o professor necessita de conhecimentos e práticas que ultrapassem o campo de sua especialidade, para viver a atitude pedagógica interdisciplinar" (HAAS, 2011, p.63). 
Nessa perspectiva, entende-se que em uma aula de Química, por exemplo, muitas vezes é preciso recorrer a conhecimentos de outras disciplinas para a compreensão mais ampla de um determinado tema.

Para facilitar o desenvolvimento de propostas interdisciplinares e mostrar o caráter cultural, humano, histórico e social da ciência, o uso de um conto de ficção científica em sala de aula pode ser uma escolha bastante proveitosa.

Soares (2007) explica que conto é uma forma narrativa menor que um romance ou uma novela e "ao invés de representar o desenvolvimento ou o corte na vida das personagens, visando abarcar a totalidade, o conto aparece como uma amostragem, como um flagrante ou instantâneo, pelo que vemos registrado literariamente um episódio singular e representativo" (SOARES, 2007, p.54). Nessa perspectiva, o conto em sala de aula apresenta a vantagem de não necessitar de muitas aulas para ser apresentado e lido em sala de aula.

A obra de ficção científica pode ser encarada como forma de expressão de discursos sobre ciência, à medida que expressa questões científicas que influenciam a sociedade e de veiculação de "posições, ideias e debates em torno de temas científicos atuais (...) empregando uma racionalidade do tipo científica para produzir conjeturas sobre a realidade" (PIASSI e PIETROCOLA, 2009, p. 526 e 528 ). 
Brunner (1971), apud Piassi e Pietrocola (2008, p.2), coloca que o aspecto educacional mais importante fornecido pelo gênero de ficção científica é a abordagem de problemas sociais. Dessa forma, este gênero aborda problemas de seres humanos em seu contexto social em que a ciência tem um papel importante.

A literatura de ficção científica muito tem a dizer sobre ciência, história e sociedade, de uma forma diferente de um texto não-literário. Piassi e Pietrocola (2009) explicitam razões para o uso de narrativas de ficção científica no ensino, diferenciando-as do uso de textos nãoliterários: maior envolvimento do leitor com as formas de expressão e com a história contada; presença contundente de sentimentos que estimulam a imaginação e a criatividade; estabelecimento de um diálogo entre razão e emoção. "É na leitura crítica que a irrealidade da ficção se torna realidade sociocultural, já que toda obra literária fala da experiência humana de forma legítima, travestindo a realidade em fantasia” (IDEM, p.538).

É possível pensar no uso de um texto de ficção científica para potencializar a aproximação entre "as duas culturas”, à medida que essa ficção se relaciona com a vida, estimulando a imaginação, a reflexão, o senso crítico, a percepção de mundo e o estabelecimento de sentidos extraídos do texto, a partir de possíveis entendimentos e interpretações do leitor. Para o estudante, é um ca- 
minho que oferece possibilidades de envolvimento que vão além do uso da razão.

Estamos tratando aqui de localizar uma característica da ficção científica que facilite a mediação entre conceitos de ciências da natureza e conhecimento do mundo histórico e social. Piassi e Pietrocola (2009, p.528) explicam que um fato extraordinário, que cause espanto, estranhamento ou admiração no leitor, mobiliza o pensamento do leitor levando-o a pensar sobre o assunto tratado e facilita o estabelecimento de conexões com a realidade. Entretanto, esse fato, que se contrapõe aos fatos conhecidos fora da ficção, está inserido em uma lógica científica dentro da ficção e relaciona-se com as questões humanas, históricas e sociais presentes no enredo. Dessa forma, o enredo da ficção científica traça um emaranhado entre princípios das leis naturais com questões que podem nos levar a pensar sobre o ser humano, seu passado, seu presente, seu futuro e suas relações sociais mobilizando razão, emoção e imaginação no leitor. Com isso a leitura crítica é estimulada, pois é a partir dela que esse emaranhado pode ser desvelado. Piassi e Pietrocola (IDEM, p.538) consideram que a compreensão de estratégias narrativas e significados não percebidos favorecem a reflexão, contribuindo assim para o desenvolvimento do pensamento crítico.

Para que o ensino caminhe no sentido de auxiliar o estudante a entender a sociedade em que vive e refletir 
sobre as possibilidades de sua transformação, é importante que ele compreenda a construção do conhecimento científico como um fazer sócio-histórico e cultural, e para isto a prática interdisciplinar que aproxime "as duas culturas" é fundamental. De acordo com Snow (1995, p.128), a educação pode considerar a experiência da criatividade tanto no fazer científico quanto no artístico ao mesmo tempo em que leva em consideração a aplicação da ciência na sociedade, o sofrimento de quem é privado dos recursos materiais fundamentais à qualidade de vida e a responsabilidade inerente ao uso do conhecimento científico. Um conto de ficção científica traz elementos que permitem trabalhar todos esses aspectos junto com o conteúdo científico, podendo ser um rico mediador na aproximação entre Química, Literatura, História e Sociologia.

\section{Desenvolvimento}

O conto de ficção científica Água de Nagasáqui "foi escrito em 1963 por Domingos Carvalho da Silva (1915-2003), escritor português que veio para o Brasil em 1914" (CAUSO, 2007). Apresenta a narração de um sobrevivente do lançamento da bomba atômica na Segunda Guerra Mundial em uma cidade próxima a Nagasáqui. O protagonista sobrevivente chama-se Takeo Matusaki, que bebe a água de um riacho da região e desde então passa a ser a causa da morte de várias pessoas por ter bebido a 
água "nagasaquiada" (contaminada com material radioativo).

Apesar de o personagem ser japonês, a história tem "um estilo brasileiro" (GAMA, 2017, p.9) porque é contada por um amigo que Takeo conheceu no Brasil e leu, decifrou e traduziu uma carta deixada pelo protagonista japonês antes de morrer.

Gama (2017) analisa o conto Água de Nagasáqui de forma a evidenciar a imagem que se tem sobre os sobreviventes da bomba nuclear em Hiroshima e Nagasáqui (chamados de hibakushas ${ }^{1}$ ). Ele associa os filmes de ficção científica Gojira (1954) e $O$ monstro da bomba $H$ (1958), escritos poucos anos antes do conto, à criação de uma alegoria sobre o homem japonês vítima da tragédia sendo visto como um monstro. Água de Nagasáqui também traz o estigma vivido por um hibakusha, visto como um perigo muitas vezes por medo e ignorância das pessoas. $\mathrm{O}$ autor relaciona a imagem estigmatizada do japonês, o medo proporcionado pela situação e a ignorância em relação ao conhecimento científico.

\footnotetext{
${ }^{1}$ Hibakusha é uma expressão japonesa usada para se referir às vítimas do lançamento das bombas atômicas na Segunda Guerra Mundial. Esses indivíduos sofrem não só pelos efeitos da radiação, mas muitas vezes pelo preconceito e ignorância das pessoas, pela falta de oportunidades de emprego e dificuldades de estabelecimento de vínculos familiares. Desde a tragédia das bombas, os hibakushas lutam por direito a indenização e tratamento médico, conseguindo vitórias significativas ao longo do tempo através de movimentos organizados.
} 
O produto educacional ${ }^{2}$ gerado com base neste conto é um Caderno Pedagógico para o professor, gerado a partir de dados e reflexões oriundos de duas práticas de ensino, descritas por Oliveira e Santos (2017) e Oliveira e Santos (2019). As manifestações dos estudantes participantes, através de discursos orais e principalmente através de suas escritas, mostraram boa receptividade pelo trabalho de ensino realizado e envolvimento com o enredo. Também promoveu o levantamento de dúvidas e discussões referentes a conceitos científicos sobre radiação e radioatividade, o contexto histórico do final da Segunda Guerra, as motivações dos cientistas que contribuíram para a construção das bombas atômicas, reflexões sobre a situação do protagonista do conto e suas atitudes, o isolamento vivido pelo protagonista representando o drama de muitos sobreviventes japoneses, o papel do conhecimento científico no combate à discriminação.

A primeira parte apresenta os referenciais teóricos do trabalho, norteando o desenvolvimento do mesmo pelas ideias de que ciência também é cultura e produção humana, pela necessidade de relacionar saberes de dife-

${ }^{2} \mathrm{O}$ produto educacional pode ser acessado clicando em Pablo Wolf Oliveira Produto.pdf - Google Drive ou acessando https://www.iq.ufrj.br e navegando em Pós-graduação/Mestrado em Ensino de Química-Modalidade Profissional/Egressos/Ano 2019. 
rentes áreas de conhecimento e por uma visão de educação crítica e transformadora.

A segunda parte explica o enredo do conto trabalhado e o contexto histórico e social relacionado a ele. Também fala sobre a vida de alguns cientistas que trouxeram conhecimentos importantes para a construção das bombas atômicas e/ou que participaram diretamente do Projeto Manhattan e o ensino de radioatividade.

A terceira parte apresenta cinco sugestões de atividades baseadas no conto e nos contextos relacionados a ele que podem ser desenvolvidas em sala de aula. Essas atividades fomentam a leitura e discussão do conto, o surgimento de questionamentos e reflexões sobre os assuntos abordados a partir da leitura do conto, o entendimento da contaminação radioativa a partir do conto, a discussão sobre o isolamento social e a discriminação, conhecimentos e reflexões sobre as motivações e atitudes dos cientistas que ajudaram direta ou indiretamente, intencionalmente ou sem intenção, na construção das bombas. Essas atividades foram realizadas em duas práticas de ensino antes da elaboração do produto educacional aqui colocado.

De uma forma resumida, as cinco sugestões de atividades contidas no Caderno Pedagógico foram: 
a) Explorando o conto em uma roda de conversa: a atividade tem como objetivo promover a expressão e socialização das principais ideias trazidas pelos estudantes a partir da leitura do conto. Assim, os estudantes colocarão o que chamou a atenção no conto tanto em relação ao enredo quanto a palavras e expressões presentes, as dúvidas e questionamentos que ele teve, se ele percebeu a relação entre o enredo, o contexto histórico e com conhecimentos de radioatividade.

b) Consequências da contaminação radioativa no ambiente: o objetivo é estabelecer relações entre o conto e a contaminação radioativa no ambiente e nos seres vivos explorando trechos do conto pertinentes ao tema.

c) Discutindo o drama social representado pelo protagonista do conto: o objetivo é proporcionar a compreensão de que o conhecimento científico não justifica o preconceito e a exclusão na sociedade dos sobreviventes do lançamento das bombas no Japão através de perguntas que relacionam trechos do conto com a questão social desses sobreviventes. O conceito científico de contaminação radioativa e irradiação é importante neste contexto porque explica o fato de as pessoas que sofrem a contaminação precisam receber tratamento médico para descontaminação e reestabelecimento da saúde, mas não respalda o seu isolamento definitivo, pois elas não se tornam fontes de radiação. 
d) O julgamento de Takeo, o protagonista do conto: o objetivo é promover reflexões sobre as atitudes individuais dos seres humanos em torno de problemas que afetam a coletividade. Para isso, a atividade é propor que os alunos apresentem argumentos que considerem o protagonista inocente em relação aos fatos fictícios do conto e argumentos que o considerem culpado. A aquisição do conhecimento científico e a percepção dos acontecimentos por parte de Takeo precisam ser pontos levantados para a continuidade da discussão.

e) O julgamento dos cientistas: o objetivo é promover a reflexão sobre as responsabilidades dos cientistas diante da sociedade. Para isso, é importante o conhecimento sobre o contexto histórico e social vivido por cada cientista, a sua cota de colaboração para a construção das bombas, suas angústias, motivações, interesses e conhecimentos sobre o projeto Manhattan, seus objetivos e contribuições para o desenvolvimento científico e tecnológico. $\mathrm{O}$ aluno é convidado a apresentar argumentos a favor e contra determinados cientistas e a se posicionar em relação ao fato de o cientista ser culpado ou inocente em relação às consequências do lançamento das bombas.

Depois da elaboração deste caderno pedagógico ele foi entregue a 4 professores de Química, 2 professores de História, 2 professores de Língua Portuguesa e Literatura e 2 professores de Sociologia, acompanhado de um questionário para ser respondido por cada um deles. $\mathrm{O}$ 
objetivo do questionário foi verificar se na visão desses professores o produto é aplicável em suas respectivas escolas e realidades de ensino com foco no público-alvo, que são os alunos.

Apesar de o produto ter sido feito com o intuito de estimular todos os professores para o desenvolvimento de atividades deste tipo, escolheu-se as quatro disciplinas mencionadas acima porque o material abarca melhor pontos específicos delas. Entretanto é preciso evidenciar que a Física e a Filosofia permeiam todo o trabalho, pois conhecimentos e reflexões referentes a esses campos de estudo estão presentes em muitos momentos. Em relação à Física, nos próprios conceitos referentes à radioatividade e no caso da Filosofia na relação entre as atitudes humanas e o desenvolvimento e uso do conhecimento científico e reflexões envolvendo ética e valores. Sendo assim, professores dessas duas e de outras disciplinas também poderiam ter sido convidados a responder o questionário, mas optou-se por delimitar esta parte da pesquisa às quatro disciplinas já citadas tendo em vista as possíveis relações entre essas quatro e as demais. De qualquer forma, foram contemplados nesta parte da pesquisa professores de Química representando as Ciências da Natureza e professores de Língua Portuguesa e Literatura, História e Sociologia representando Ciências Humanas e Linguagens. 
A partir de questionário aplicado a professores do Ensino Médio no Estado do Rio de Janeiro, coloca-se aqui a visão desses professores sobre a aplicabilidade das propostas apresentadas no Caderno Pedagógico levando em consideração a percepção deles em relação às escolas em que eles trabalham e aos alunos que eles têm.

Primeiro foram colocadas as visões dos quatro professores de Química (PQ), que chamaremos de grupo 1, obtidas pelas respostas ao questionário. Depois o mesmo procedimento foi feito com relação aos professores de Língua Portuguesa (PL), História (PH) e Sociologia (PS), que chamaremos de grupo 2.

Em relação à aplicabilidade das atividades pelos professores do grupo 1, apresentamos algumas considerações e dados importantes a seguir.

O professor PQ1 aplicaria as atividades marcadas na escola pública com Educação Profissional, pois segundo ele oferece, relativamente, condições materiais e de tempo para o desenvolvimento das atividades. Os demais professores aplicariam em todas as suas escolas.

As atividades que mais poderiam ser aplicadas pelos professores de Química foram A1 e A2. Vale ressaltar que são as propostas que menos exigem conhecimentos específicos de disciplinas da área de humanas. A ati- 
vidade A2 é a que aborda diretamente conteúdos de Química.

Os comentários referentes às possíveis dificuldades e necessidades para a realização das atividades foram:

PQ1: Tempo necessário para desenvolver estas atividades $e$ todas as demais já previstas.

PQ1: Na escola pública estadual o tema de radioatividade aparece disperso no estudo dos modelos atômicos (primeiro ano) e no estudo de cinética (segundo ano).

PQ1: Na escola com ensino médio integrado à educação profissional existe uma maior flexibilidade para abordar os conteúdos e melhor acesso a materiais digitais.

PQ1: Apesar de achar as atividades 4 e 5 interessantes, creio que necessitaria de mais tempo para aplicá-las. Talvez com a colaboração de um colega de outra disciplina seria mais viável.

PQ2: Apesar de ter marcado todas as atividades, inicialmente, acredito que só seria possível em um trabalho conjunto com o professor de Sociologia. O tempo de aula e o plano de curso são fatores limitantes. Além disso, falta espaço no ambiente escolar para encontro com professores de outras disciplinas como Literatura e Sociologia. Na minha escola a proposta de trabalho conjunto poderia ser feita sob o título de Projeto Interdisciplinar.

PQ2: Todas as atividades são interessantes, porém, me sentiria preparada para aplicar as dos itens 1 e 2. As atividades 3, 
4 e 5 eu passaria para o professor de Sociologia e, dessa forma, desenvolveríamos um trabalho interdisciplinar.

PQ3: O professor deve ter razoável segurança a respeito do contexto histórico-social relacionado ao texto para que consiga realizar uma discussão profunda e reflexiva entre os discentes.

PQ4: Acredito que seja possível realizar as atividades em todas as turmas, mas na escola particular por causa de um planejamento mais apertado e engessado seria mais difícil. Talvez fosse possível usá-lo como parte de um projeto.

PQ4: Seria possível aplicar todas as atividades sozinha ou dividir com outro professor ou ainda adaptar as atividades de acordo com o tempo disponível.

PQ4: Acho que seria interessante um professor da área de humanas para ajudar a mediar alguns debates.

De acordo com as escritas acima, os fatores que precisam ser levados em conta na aplicação das atividades propostas são: tempo disponível, colaboração de professores de outras disciplinas, disponibilidade de recursos didáticos, flexibilização do planejamento dos conteúdos, conhecimento do professor para lidar com os conteúdos de outras disciplinas e possibilidade de desenvolvimento de projetos interdisciplinares.

Com relação à aplicação das propostas de forma colaborativa com outros professores, observamos alguns comentários: 
PQ2: Aplicaria, num primeiro momento, sozinha, apesar de achar as ideias muito interessantes para um projeto interdisciplinar.

PQ4: O planejamento das atividades dependeria da disponibilidade de tempo e de outros professores.

Também foram apresentadas sugestões para o trabalho, conforme colocado a seguir:

PQ1: Outra atividade possível seria a síntese dos elementos transurânicos junto com o estudo da tabela periódica.

PQ4: A série Chernobyl da HBO pode ser mais uma fonte para auxiliar no debate do tema.

Todos os professores dizem que o Caderno Pedagógico esclarece bem a proposta de ensino e o desenvolvimento das atividades. Os comentários obtidos foram:

PQ1: As considerações estão bem detalhadas.

PQ3: O texto apresentado traz bastante lucidez, de modo que permite, sim, a possibilidade de aplicação no contexto escolar.

Com a análise das percepções dos professores de Química participantes desta pesquisa, foi possível observar que as propostas contidas no Caderno Pedagógico foram bem recebidas, mostrando-se receptivos a esses conhecimentos e reflexões que vão além da Química. O professor PQ1 trabalhou com o conto em uma de suas 
turmas de Ensino Médio Integrado à Educação Profissional um mês após responder ao questionário. A ideia de aprofundar o assunto com a questão de Chernobyl também amplia e enriquece o trabalho, favorece o desenvolvimento de questões sócio-históricas e a interdisciplinaridade.

Com relação à aplicabilidade das propostas de atividades do Caderno Pedagógico pelos professores do grupo 2, os comentários referentes às possíveis dificuldades e necessidades para a realização das atividades foram:

PL1: Não creio que haja dificuldades. Os alunos receberam bem o conto, passarei à etapa de análise nas próximas semanas.

PL2: Compatibilidade com o cronograma e falta de tempo disponível para o cumprimento do programa.

PH1: Não vejo dificuldades; talvez, no contexto atual da educação no Rio de Janeiro, deixaria para aplicar tais atividades no terceiro ano do Ensino Médio.

PH2: Prender a atenção dos alunos, esse é o nosso grande desafio.

Através dessas falas, os fatores identificados como sendo dificuldades para a aplicação da proposta são: compatibilidade com o cronograma de aulas, tempo disponível para aplicação sem que o cumprimento do pro- 
grama de ensino seja prejudicado e conseguir a atenção dos alunos. Observando também as dificuldades apontadas pelos professores de Química, verifica-se que uma fala aponta dificuldades de aplicação por causa dos alunos; as demais referem-se ao planejamento, aos conteúdos que precisam ser ministrados e à disponibilidade de recursos. Não tenho a pretensão aqui de descartar as possíveis dificuldades que podem ser encontradas em relação a uma possível falta de interesse ou preparo de alunos para o desenvolvimento da proposta, mas verifica-se a necessidade de destacar a importância do planejamento curricular e da existência de condições materiais e de organização do tempo e do espaço escolares. Tratando-se da realização de um trabalho envolvendo mais de um professor, essa importância torna-se ainda maior.

Foram obtidos comentários em relação às atividades sugeridas, conforme colocado a seguir:

PL2: Em relação ao item 1, a atividade, entre outros desdobramentos, possibilita uma reflexão acerca do gênero textual conto, favorecendo o reconhecimento de suas características $e$ de seus elementos estruturais. Além disso, há o trabalho de compreensão textual propriamente dito, bem como um estudo prático da interdiscursividade.

PL2: No que diz respeito ao item 3, em termos de habilidades e competências discursivas, trata-se de uma importante ferramenta para a análise da progressão da narrativa. 
PL2: Por fim, a atividade 5 favorece o exercício da argumentação, a partir da elaboração de uma tese e da composição de todo um aparato discursivo para defendê-la.

PL2: Cabe ressaltar que a preferência da atividade 5 em relação à 4 se vale do contexto da argumentação. Alusão histórica e argumentos de autoridade são estratégias argumentativas valorizadas no processo de persuasão.

PH1: Percebo que todas as atividades propostas, na minha disciplina de História teria facilidade de ação, além disso, provocaria o trabalho interdisciplinar, contribuindo assim para a aproximação de conceitos diferentes, porém complementares, como por exemplo, aliar História, Sociologia, Física, Artes, Química, Matemática e Filosofia.

PH2: Usaria nas turmas de terceiro ano de Ensino Médio, nas aulas sobre a Segunda Guerra Mundial.

PH2: Abordaria a questão da discriminação contra a mulher, cientista com a mesma capacidade dos cientistas homens, que não ganhou o Prêmio Nobel. Faria também o parâmetro entre a ciência para o bem da humanidade e a ciência para destruir a humanidade.

Observou-se que os professores de Língua Portuguesa, História e Sociologia sentem-se mais confortáveis em aplicar a proposta do que os professores de Química desta pesquisa. Inclusive, os professores PL1, PL2 e PS1 aplicaram de fato uma ou mais de uma atividade sugerida. $\mathrm{O}$ fato de os professores de humanas terem mostrado em suas falas maior desenvoltura para uma possível aplicação das propostas sugere que, neste universo de pes- 
quisa, a contextualização sócio histórica e o conto literário no ensino de Química são um desafio maior do que a discussão das ciências da natureza em aulas da área de humanas. Uma explicação possível é a de que o material elaborado está mais de acordo com os conhecimentos trabalhados e o estilo de aulas do segundo grupo. Os conteúdos sobre gênero textual, argumentação, discriminação, Segunda Guerra Mundial e reflexões sobre ciência para o bem da humanidade foram colocados por esses professores como exemplos que se relacionam a esta proposta. É preciso pensar também na importância de fomentar durante a formação inicial e continuada de professores de Química práticas de ensino, pesquisa e extensão que favoreçam a humanização da ciência.

Já em relação à possibilidade de aplicação das propostas em parceria com outros professores, os comentários obtidos foram:

PL1: Em parceria com o professor de Sociologia. realizaria um debate acerca das questões de julgamento e preconceito, movidos pela apresentação do protagonista do conto.

PS2: Esse tema, a meu ver, é bom para ser tratado em mais de uma disciplina. Dá mais concretude ao assunto.

PH1: Creio que o trabalho interdisciplinar seria mais rico e ao mesmo tempo contribuiria para atingir o objetivo das atividades. 
PH2: Aplicaria com os professores de Química, Física, Sociologia e Filosofia.

A maioria dos professores desse grupo aplicaria a proposta sozinho ou com outros professores, demonstrando maior flexibilidade nesse sentido. Entretanto, verifica-se nas falas encontradas que o trabalho interdisciplinar envolvendo mais de um professor seria mais rico e produtivo. De fato, o diálogo entre as duas culturas proposto por Snow (1995) pode ser mais efetivo quando os professores de diferentes disciplinas trabalham juntos, entretanto, tendo em vista que foram obtidos nesta dissertação resultados importantes com a aplicação da proposta por apenas um professor, sugere-se aqui que a falta da possibilidade de realização de um trabalho conjunto não deve ser um impeditivo para a aplicação das atividades sugeridas, com as adaptações devidas a cada realidade escolar.

Todos os professores afirmaram que o Caderno Pedagógico esclarece bem a proposta de ensino e o desenvolvimento das atividades. Os comentários obtidos foram:

PL1: Sem dúvida, as atividades propostas são de relevância ímpar. Vou aplicá-las nas aulas de Língua Portuguesa e Redação, bem como nas de Literatura ao trabalhar o gênero textual. 
PL2: Além de esclarecer possíveis encaminhamentos para o trabalho, há o fornecimento de informações adequadamente organizadas, confiáveis, que auxiliam o público comum/não especializado no entendimento de certos conceitos.

PS1: Excelente proposta.

PS2: O caderno esclarece bem a proposta.

As respostas dadas a esta questão sobre o esclarecimento da proposta de ensino dão mais segurança para que o presente Caderno Pedagógico possa ser divulgado para um número maior de professores.

Os professores PL1, PL2 e PS1 aplicaram pelo menos uma das propostas em alguma de suas salas de aula.

PL1: Os alunos receberam bem o conto. Passarei à etapa de análise nas próximas semanas.

PL2: O trabalho foi aplicado em turmas do programa de Educação de Jovens e Adultos.

PL2: Uma aluna, de 42 anos, fez uma analogia com o drama vivenciado pelo personagem principal. Ela citou o caso dos portadores do HIV na década de 8o, em que a ausência/falta de maior divulgação sobre a doença gerava bastante preconceito, condenando os enfermos a uma situação de isolamento.

PS1: Apliquei em uma turma e os alunos gostaram.

PS1: Usei também para falar de doenças sexualmente transmissíveis, a ideia de contágio e como se proteger. 
A professora PL1 realizou a leitura e discussão do conto com seus alunos de terceiro ano e pediu para eles realizarem uma produção textual a respeito da responsabilidade do protagonista e se preocupou em levar um pouco de conhecimento científico ao trabalhar um texto informativo explicando a diferença entre a explosão das bombas no Japão e a do reator em Chernobyl. Já o professor PL2 focou a discussão do texto e a argumentação baseada na vida dos cientistas em turmas de Educação de Jovens e Adultos. A professora PS1 trabalhou em turmas de terceiro ano enquanto ministrava o conteúdo de conceito de Estado, Estado totalitário, nazismo e fascismo, passando pela questão da discriminação e ampliando a mesma para o contexto da propagação de doenças sexualmente transmissíveis.

Verificou-se nas falas de dois professores (PL2 e PS1) que o trabalho deu oportunidade à discussão sobre HIV e contágio. O isolamento social é uma realidade de várias pessoas que têm o vírus HIV, pois enfrentam preconceito e isso gera exclusão. Assim como no caso de Takeo, o portador de HIV também pode sofrer preconceito por falta de informação científica de pessoas do seu convívio por estas acharem que serão contaminadas pelo simples convívio, fato constantemente desmentido por diversos trabalhos de divulgação científica. O conhecimento científico pode ser um poderoso aliado no combate ao preconceito e atitudes inadequadas e perniciosas no convívio social. 
A questão da exclusão existe em diversos contextos, como por exemplo, no fato de alguém ter uma doença, pelo preconceito por questões de etnia, cor de pele, sexo, orientação sexual e outras. Atualmente (2020) enfrenta-se uma pandemia onde o distanciamento social é necessário para preservar vidas e nessa situação as desigualdades sociais e a falta de condições básicas de subsistência deixam muitas pessoas mais vulneráveis à pandemia. Sendo assim, podemos pensar que a verdadeira exclusão não é causada pelo distanciamento necessário, mas pela falta de atendimento às pessoas em situações de vulnerabilidade social, potencializando problemas de saúde, alimentação e falta de renda. Dessa forma, a questão da exclusão é um ponto marcante no conto e que pode ser trabalhada a partir do mesmo.

Também foram apresentadas sugestões para o trabalho, conforme colocado a seguir:

PL1: Pode ser acrescentado à proposta o desenvolvimento de uma produção textual acerca dos eixos abordados. Seria bem interessante.

PL1: Além de abordar os itens propostos em uma atividade de debate e/ou roda de conversa, eu utilizaria o eixo do drama social/estereótipo conferido ao protagonista para a elaboração de uma produção de texto, bem como a elaboração de propostas de solução no modelo ENEM. 
PS2: Em política, pode-se estudar a relação entre a produção científica e as relações de poder. "A quem serve a ciência?" é uma questão a ser levantada.

PS2: Acho interessante ter mais perguntas aos alunos e mais sugestões de atividades. Exemplo: Em que áreas a ciência se desenvolve mais? Por quê? Qual a relação disso com o poder econômico?

É possível confirmar com essas falas que o Caderno Pedagógico está longe de abordar todas as possibilidades de trabalho com o conto escolhido. Nas considerações finais do Caderno citou-se as sugestões recebidas aqui para que os professores que lerão o material possam vislumbrar outras possibilidades. Este material não foi feito com o objetivo de trazer receitas prontas para aplicação em sala de aula, mas fomentar o desenvolvimento de diferentes possibilidades de acordo com cada realidade de ensino.

A proposta do Caderno Pedagógico e as colocações dos professores aqui mostradas podem nos ajudar a perceber que é possível resgatar as ideias de Charles Percy Snow de união entre o que ele chamou de cultura científica e cultura humanística bem como o que ele coloca como Terceira Cultura e trazê-las de uma forma mais concreta para a escola e a sala de aula. O diálogo entre Ciências Humanas e Ciências da Natureza torna-se não apenas possível, mas principalmente necessário para que seja possível a compreensão de diversos fatos e fenôme- 
nos existentes no mundo em que vivemos. Percebe-se que o entendimento da questão da construção das bombas atômicas e dos sobreviventes da explosão no Japão passa pelo conhecimento sobre radioatividade e seus efeitos no organismo (Ciências da Natureza) e pela compreensão do processo histórico, das relações sociais e da ética envolvida nas ações (Ciências Humanas e Filosofia) de forma mais integrada. A História das Ciências mostrada através da biografia dos cientistas e de reflexões sobre suas vidas e suas ações também é um fator importante na construção desse diálogo. A Terceira Cultura de Snow pode ser colocada como a formação de um indivíduo que não é limitada apenas a uma especialização de saber, mas que contempla uma formação mais abrangente. Nesse sentido, defende-se aqui que no Ensino Médio o aluno deve ter uma formação ampla, e que a profissionalização e a busca pelos gostos e talentos dos estudantes nessa fase não devem ser motivos para restringir-lhes a formação geral e fazer com que eles só se dediquem a uma determinada área do conhecimento por um bom tempo desse nível de ensino. A formação geral, ampla e diversificada deve continuar sendo um direito do aluno, que precisa ser capaz de entender o mundo com as ferramentas oferecidas por diferentes ciências e linguagens.

O conto de ficção científica é transdisciplinar, ou seja, é organizado de forma a ultrapassar a organização das próprias disciplinas. Em um trabalho interdisciplinar no ambiente escolar, cada disciplina tem a sua contribui- 
ção a dar para o diálogo entre conhecimentos necessários à compreensão do enredo. Em aulas de Química, por exemplo, além dos conceitos químicos envolvidos, conceitos de outras disciplinas podem vir à tona para dar maior consistência e fundamentação ao tema, bem como mostrar a relevância do conhecimento químico em um determinado contexto. Foi possível perceber que os professores visualizaram o aproveitamento do conto para o trabalho em suas respectivas disciplinas e perceberam o potencial de trabalho interdisciplinar contido nas sugestões apresentadas.

O papel do uso de um conto no lugar de um texto informativo não foi apontado aqui nesta pesquisa, mas em trabalhos desenvolvido com alunos (OLIVEIRA, 2019) foi possível perceber o envolvimento favorecido pelo enredo, pela ficção, pelas palavras e pela narrativa. Com isso, pode-se pensar que o uso do conto pode favorecer o desenvolvimento das ideias pelo trabalho com as emoções, com a imaginação, com o incentivo à imaginação e tudo isso pode ser relacionado ao contexto científico e sócio-histórico trabalhado. Vale ressaltar que o conto teve um papel fundamental na mediação entre conteúdos de Ciências da Natureza com Ciências Humanas.

É possível perceber que a proposta apresentada no produto educacional fomenta a abertura de uma determinada disciplina escolar para conhecimentos de outras disciplinas e fornece subsídios para ajudar o profes- 
sor no desafio de dialogar com seus conteúdos disciplinares e com outros conhecimentos e torná-los mais significativos ao conectar conteúdo científico a reflexões humanas e sócio-históricas.

\section{Conclusões}

O Caderno Pedagógico aqui apresentado é uma proposta de concretizar na prática de ensino o desafio de mostrar a ciência como parte da cultura e produto das ideias, motivações e atitudes humanas, bem como a de fomentar atitudes interdisciplinares. Para isso, coloca-se o potencial pedagógico de um conto de ficção científica em mobilizar a sensibilidade ao mesmo tempo em que fomenta o desenvolvimento de conteúdos de radioatividade, o conhecimento de fatos históricos e as relações entre os indivíduos e a sociedade em que vive; instiga o confronto entre a lógica da ficção e o conhecimento científico e incentiva o hábito da leitura.

De acordo com a análise das percepções dos professores em relação à aplicabilidade do Caderno Pedagógico, foi possível verificar que os docentes receberam bem a proposta desenvolvida e mostraram-se abertos a realizarem atividades interdisciplinares, sozinhos ou com outros professores. 
Espera-se que o presente produto contribua para motivar professores do Ensino Médio a desenvolverem conhecimentos e reflexões ao mesmo tempo em que apresentam aos alunos a riqueza da literatura de ficção científica.

\section{Referências}

ALMEIDA FILHO, N. de. As três culturas na Universidade Nova. Revista do Instituto de Ciência da Informação da UFBA. Salvador, v.1, n.1,2007, p 5-15.

CAUSO, R. de S. (ed.). Os melhores contos brasileiros de ficção científica. São Paulo: Devir,2007.

CORDIOLLI, M. A relação entre disciplinas em sala de aula (a interdisciplinaridade, a transdisciplinaridade e a multidisciplinaridade. Curitiba: A Casa de Astérion,2002.

GAMA, V C. Água de Nagasáqui: o japonês na ficção científica brasileira. HON NO MUSHI. Estudos Interdisciplinares japoneses.Vol.2, n.3,2017.

GURGEL, I.; WATANABE, G. A elaboração de narrativas em aulas de Física. A aprendizagem em ciências como manifestação cultural. São Paulo: livraria da Física, 2017.

HAAS, C. M. A Interdisciplinaridade em Ivani Fazenda: a construção de uma atitude pedagógica. International Studies on Law and Education.Univ.do Porto, mai-ago,2011. 
OLIVEIRA, E. B. de; SANTOS, F. N. dos. 5 pressupostos e definições em interdisciplinaridade: diálogo com alguns autores. Interdisc. São Paulo, n.11, p.1-151, out.2017.

OLIVEIRA, E. de; ALVES, A. F. Uma análise literária sobre o conceito de cultura. Revista Brasileira de Educação e Cultura. Centro de Ensino Superior de São Gotardo, n. XI, jan -jun. 2015, p.1-18.

OLIVEIRA, P. W. Aproximando conhecimentos e reflexões sobre ciência, história e sociedade ao ensino de Química através de um conto de ficção científica. 215f. Dissertação (Mestrado Profissional em Ensino de Química). Instituto de Química, Universidade Federal do Rio de Janeiro, Rio de Janeiro, 2019.

OLIVEIRA, P. W.; SANTOS, N. P. dos. Considerações sobre o uso de um conto de ficção científica no ensino de Química: radioatividade. In: MIRANDA, J. L. de; et.al. (org.). Ensino de Química em revista: o papel social do Ensino de Química. Rio de Janeiro: UFRJ, Instituto de Química, 2017. Disponível em: $<$ https://issuu.com/waldmir.neto/docs/livro_pequi_2017>. Acesso em 21 de outubro de 2020.

OLIVEIRA, P. W.; SANTOS, N. P. dos. Uma abordagem sobre o tema radioatividade aproximando questões sócio-históricas ao ensino de Química através de um conto de ficção científica. In: SIMPEQUI, $2019 . \quad$ Disponível em: <http://www.abq.org.br/simpequi/2019/trabalhos/90/44227544.html > Acesso em 21 de outubro de 2020.

PIASSI, L. P. de C.; PIETROCOLA, M. Ficção científica e ensino de ciências: para além do método de encontrar erros em filmes. Educação e Pesquisa. São Paulo, v.35, n.3, p.525540,2009 . 
Questões sócio políticas de ciência através da ficção científica: um exemplo com "contato". XI Encontro de Pesquisa em Ensino de Física. Curitiba, 2008, p.1-12.

PIMENTEL, J. ¿Que es la historia cultural de la ciencia? ARBOR Ciência, Pensamiento y cultura. Madrid, maio- junho, 2010.

SNOW, C.P. As duas culturas e uma segunda leitura. São Paulo: Edusp,1995.

THIESEN, J. da S. A interdisciplinaridade como um movimento articulador no processo ensino-aprendizagem. Revista Brasileira de Educação.V.13, n.39, set/dez. 2008. 